\title{
Atividade antiviral de extratos de plantas medicinais disponíveis comercialmente frente aos herpesvírus suíno e bovino
}

\author{
KAZIYAMA, V.M.; FERNANDES, M.J.B.; SIMONI, I.C.* \\ Centro de Pesquisa e Desenvolvimento de Sanidade Animal, Instituto Biológico, CEP: 04014-002, São Paulo- \\ Brazil *simoni@biologico.sp.gov.br
}

\begin{abstract}
RESUMO: O presente trabalho teve como objetivo pesquisar a atividade antiviral in vitro de plantas medicinais disponíveis comercialmente sobre herpesvírus suíno (SuHV-1) e bovino (BoHV-1). As espécies adquiridas foram Mikania glomerata, Cymbopogon citratus, Equisetum arvense, Peumus boldus, Solanum paniculatum, Malva sylvestris, Piper umbellatun e Solidago microglossa. A citotoxicidade dos extratos foi avaliada na linhagem celular MDBK pelas alterações morfológicas das células e obtenção da concentração máxima não citotóxica (CMNC) de cada planta. A atividade antiviral foi realizada com os extratos em suas respectivas $\mathrm{CMNC}$ e avaliada com base na redução do título viral e expressos em porcentagem de inibição. Os extratos aquosos de Peumus boldus e Solanum paniculatum apresentaram atividade antiviral sobre o SuHV-1 com $98 \%$ de inibição viral enquanto o de Peumus boldus inibiu apenas o BoHV-1 em 99\%.
\end{abstract}

Palavras-chave: Herpesvírus bovino e suíno, plantas comerciais, citotoxicidade, antiviral

\begin{abstract}
Antiviral activity of commercially available medicinal plants on suid and bovine herpesviruses. This paper aims to find commercially available medicinal plants showing antiviral activity in vitro on suid and bovine herpesviruses. The following species were tested: Mikania glomerata, Cymbopogon citratus, Equisetum arvense, Peumus boldus, Solanum paniculatum, Malva sylvestris, Piper umbellatun and Solidago microglossa. The cytotoxicity was evaluated by morphological changes in cells determining the maximum not cytotoxic concentration (MNCC). The antiviral activity was evaluated by viral title reduction. The extracts from Peumus boldus and Solanum paniculatum showed antiviral activity against SuHV-1 with $98 \%$ of inhibition. The extract of Peumus boldus also showed activity against BoHV-1 with $99 \%$ of inhibition.
\end{abstract}

Key words: Bovine and suid herpesviruses, marketable plants, cytotoxicity, antiviral

\section{INTRODUÇÃO}

A maioria das doenças infecciosas que afeta o homem e o animal é causada por vírus e ainda representam um risco à saúde publica apesar de todo progresso na medicina. Além disso, na área veterinária, estas doenças virais são responsáveis por grandes perdas econômicas, incluindo-se as causadas pelos vírus da família Herpesviridae.

O herpesvírus suíno (SuHV-1) é responsável pela doença de Aujeszky ou pseudo-raiva que se constitui em um grande obstáculo à exploração e ao comércio internacional de suínos. Em animais jovens os sinais clínicos predominantes são os neurológicos com taxa de mortalidade aproximando-se dos $100 \%$. Animais adultos apresentam febre, taxas variáveis de aborto, reabsorção fetal, dificuldade respiratória e eventualmente vômitos. A mortalidade nessa faixa etária é baixa. Além disso, a doença de Aujeszky possui importância sanitária e é de notificação anual obrigatória, sendo necessária sua erradicação (Groff et al., 2005). O herpevírus bovino (BoHV-1) é responsável pela rinotraqueíte infecciosa bovina (IBR) e por uma variedade de outras síndromes associadas aos sinais clínicos, tais como conjuntivite, encefalite, infecções respiratórias (pneumonia), vulvovaginite pustular nas fêmeas, balanopostite nos machos e diversas formas de problemas reprodutivos como mortalidade embrionária e fetal, abortamento, natimortalidade e nascimento de bezerros fracos (Del Fava et al., 1998; Takiuchi et al., 2003; Spilki et al., 2004; Ackermann \& Engels, 2006). Além disso, provoca imunossupressão que induz a infecções bacterianas secundárias, causadoras da pneumonia (Jones, 2003). As

Recebido para publicação em 01/12/2010

Aceito para publicação em 24/01/2012

Rev. Bras. PI. Med., Botucatu, v.14, n.3, p.522-528, 2012. 
enfermidades causadas pelo herpesvírus bovino provocam sérios prejuízos para a indústria de gado, relacionados ao aborto, baixa fertilidade de machos e fêmeas, crescimento retardado nos animais jovens que adquirem rinotraqueíte, queda da produção de leite, entre outras (Del Fava et al., 1998; Spilki et al., 2004). A propriedade biológica de maior importância destes dois vírus é a capacidade de estabelecer infecções latentes no sistema nervoso do hospedeiro após a infecção aguda, persistindo por toda a vida do animal. Essa latência pode ser reativada resultando em excreção e transmissão de vírus (Del Fava et al., 1998; Médici et al., 2000; Jones, 2003; Barbosa et al., 2005; Groff et al., 2005; Silva et al., 2005).

No controle e prevenção das infecções virais são utilizadas vacinas. Entretanto a vacinação de bovinos e suínos apenas minimiza as manifestações clínicas destas doenças, ou seja, não impedem a latência e a eliminação do vírus já instalado. Assim, muitos animais soropositivos são descartados com o objetivo de erradicação da doença (Cunha et al., 1998; Del Fava et al., 1998; Ackermann \& Engels, 2006).

A utilização de plantas como fonte de substâncias antivirais é uma das alternativas para o controle e tratamento de infecções virais. A seleção de espécies vegetais a partir de dados etnofarmacológicos para estes estudos fornece percentual maior de descoberta de novos compostos bioativos (Di Stasi et al., 1996; Yunes \& Calixto, 2001; Maciel et al., 2002). Entretanto, a disponibilidade do material vegetal pode dificultar as pesquisas com produtos naturais, principalmente daquelas espécies que podem estar em risco de extinção, em consequência do extrativismo, desmatamento e da degradação ambiental (Simões et al., 2004). Além disso, para a identificação do princípio ativo é necessária grande quantidade de matéria prima, a fim de realizar o fracionamento e determinação dos compostos químicos (Yunes \& Calixto, 2001).

Deste modo, a utilização de plantas medicinais cultivadas pode minimizar este problema. As principais vantagens de se estudar plantas medicinais cultivadas são os produtos de alta qualidade, produção em alta escala fornecendo grande quantidade de matéria prima, baixo custo e preservação do meio ambiente; também se obtém a homogeneidade dos compostos químicos, já que a forma de cultivo, a adaptação da planta a determinadas condições de clima, solo, altitude, fertilidade podem influenciar a composição das substâncias nas plantas (Di Stasi et al.,1996; Sartório et al., 2000).

O presente trabalho tem como objetivo pesquisar produtos naturais provenientes de plantas medicinais disponíveis comercialmente que apresentem atividade antiviral em linhagem celular de rim de bovino (MDBK) sobre herpesvírus suíno e bovino.

\section{MATERIAL E MÉTODO}

\section{Vírus e células}

A linhagem celular MDBK de rim de bovino (ATCC-CCL 22) foi mantida em meio Eagle mínimo (MEM) acrescido de $10 \%$ de soro fetal bovino. As amostras virais utilizadas foram herpesvírus bovino (BoHV-1), cepa Los Angeles (Straub, 2001) e herpesvírus suíno (SuHV-1), cepa Nova Prata gentilmente cedida pelo Instituto Desidério Finamor, RS, Brasil (Fonseca Junior et al., 2010).

\section{Extratos de plantas}

As plantas Mikania glomerata, Cymbopogon citratus, Equisetum arvense, Peumus boldus, Solanum paniculatum, Malva sylvestris, Piper umbellatun e Solidago microglossa foram adquiridas comercialmente da empresa Napiê, com um certificado de análise garantindo a pureza e com as especificações conforme relacionado na Tabela 1. O material vegetal a partir das folhas foi recebido seco e moído.

\section{Preparo dos extratos}

Extratos aquosos (EA) de todas as plantas foram preparados a $10 \%$ a frio por uma noite. Após esse período, EA foram filtrados com o auxílio de gaze e papel filtro. Apenas para a planta Peumus boldus foi preparado também o extrato etanólico (EE), obtido por maceração a frio com etanol PApor 3 vezes consecutivas. O solvente foi filtrado e evaporado sob pressão reduzida. Todos os extratos (EA e EE) foram posteriormente liofilizados e para uso nos bioensaios, foram ressuspensos em partes iguais de água ultrapura e MEM 2 vezes concentrado, para a concentração final de $4.000 \mu \mathrm{g} \mathrm{mL}^{-1}$ e filtrados em membrana Milipore 0,22 $\mu \mathrm{m}$.

\section{Teste de citotoxicidade}

A citotoxicidade dos extratos foi avaliada na linhagem celular MDBK pelo método descrito por Simoni et al. (2007). Foram empregadas microplacas estéreis, descartáveis, com 96 orifícios. Em cada orifício foram semeadas $3,0 \times 10^{4}$ células em $100 \mathrm{~mL}$ de MEM. Após 24 horas de incubação a $37^{\circ} \mathrm{C}$, em ambiente de $\mathrm{CO}_{2}$ a $5 \%$, o meio sobrenadante foi descartado e em cada orifício foi colocado $0,1 \mathrm{~mL}$ das diluições seriadas dos extratos, com pelo menos 2 repetições para cada diluição. A seguir, as microplacas foram incubadas novamente durante pelo menos $96 \mathrm{~h}$. As concentrações dos extratos iniciaram em $4000 \mu \mathrm{g} \mathrm{mL}^{-1}$ até 1,8 $\mu \mathrm{g} \mathrm{mL}^{-1}$. A concentração de cada extrato que não produziu alterações morfológicas nas células foi considerada a concentração máxima não citotóxica (CMNC).

\section{Atividade antiviral}

A atividade antiviral dos extratos na linhagem celular MDBK foi realizada segundo a metodologia 
descrita por Simoni et al. (2007) e Koseki et al. (1990). Em microplacas de 96 orifícios contendo monocamadas de células MDBK foi colocado 100 $\mathrm{mL}$ de extrato na CMNC e após 1 hora de incubação a $37^{\circ} \mathrm{C}$, em ambiente de $\mathrm{CO}_{2}$, foi colocado $50 \mu \mathrm{L}$ das suspensões virais em diluições logarítmicas; e novamente incubadas durante pelo menos $96 \mathrm{~h}$. A atividade antiviral foi testada em dois bioensaios independentes. O título viral ( $\left.\mathrm{DICC}_{50}\right)$ foi calculado pelo método de Reed \& Muench (1938) e a avaliação da atividade antiviral foi calculada pela diferença entre 0 título viral nas células infectadas e tratadas com os extratos $(T)$ pelo controle, nas células infectadas sem extrato (C) e expresso pelo índice de inibição viral (IIV) e também pela porcentagem de inibição. Quando a diferença do IIV foi igual ou maior do que 1,5 os extratos foram considerados inibidores, correspondendo a porcentagem de inibição acima de $96 \%$.

\section{RESULTADO}

As informações das plantas Cymbopogon citratus, Equisetum arvense, Malva sylvestris, Mikania glomerata, Peumus boldus, Piper umbellatun, Solanum paniculatum e Solidago microglossa com relação aos constituintes químicos, ações farmacológicas, nome popular e data da coleta foram fornecidas pela empresa Napiê e encontramse na Tabela 1. Apenas Mikania glomerata, o guaco, não teve nenhuma informação complementar sobre os constituintes químicos e ações farmacológicas.

TABELA 1. Relação dos nomes científicos e populares, constituintes ativos, ações farmacológicas e data da coleta das plantas estudadas, dados fornecidos pela empresa no certificado de análise.

\begin{tabular}{|c|c|c|c|c|}
\hline $\begin{array}{c}\text { Nome } \\
\text { científico }\end{array}$ & $\begin{array}{c}\text { Nome } \\
\text { popular }\end{array}$ & $\begin{array}{l}\text { Constituintes } \\
\text { ativos }\end{array}$ & $\begin{array}{l}\text { Ações } \\
\text { farmacológicas }\end{array}$ & $\begin{array}{l}\text { Data de } \\
\text { coleta }\end{array}$ \\
\hline $\begin{array}{c}\text { Mikania } \\
\text { glomerata }\end{array}$ & Guaco & $\mathrm{NI}$ & $\mathrm{NI}$ & $05 / 04 / 05$ \\
\hline $\begin{array}{l}\text { Cymbopogom } \\
\text { citratus }\end{array}$ & $\begin{array}{l}\text { Capim } \\
\text { Santo }\end{array}$ & $\begin{array}{l}\text { Óleo essencial (citral), alcalóides, } \\
\text { saponinas, cumarinas e flavonóides. }\end{array}$ & $\begin{array}{l}\text { Insônia, nervosismo, ansiedade, } \\
\text { psicoses, digestivo estomacal, } \\
\text { gases intestinais, febre, } \\
\text { reumatismo, contusões, dores } \\
\text { musculares, repelentes de insetos, } \\
\text { limpeza dos dentes e gengivas. }\end{array}$ & $11 / 04 / 05$ \\
\hline $\begin{array}{l}\text { Equisetum } \\
\text { arvense }\end{array}$ & Cavalinha & $\begin{array}{l}\text { Óleo essencial, cumarinas, } \\
\text { alcalóides, pigmentos e mucilagens. }\end{array}$ & $\begin{array}{l}\text { Diurética, remineralizanre, } \\
\text { antiinflamatória e adstringente } \\
\text { genito-urinário. }\end{array}$ & $02 / 04 / 05$ \\
\hline $\begin{array}{c}\text { Solanum } \\
\text { paniculatum }\end{array}$ & Jurubeba & $\begin{array}{l}\text { Alcalóides, solanina, saponinas, } \\
\text { glicosídeos, mucilagem, resinas, } \\
\text { ceras e ácidos orgânicos. }\end{array}$ & $\begin{array}{l}\text { Tônica, descongestionante, } \\
\text { diurética, estomáquico, febrífugo, } \\
\text { colagoga, emenagoga e } \\
\text { cicatrizante. }\end{array}$ & $07 / 03 / 05$ \\
\hline $\begin{array}{c}\text { Malva } \\
\text { sylvestris }\end{array}$ & Malva & $\begin{array}{l}\text { Mucilagens (pentoses), hexoses, } \\
\text { ácido galacturônico, ácidos fenólicos, } \\
\text { antocianinas (Malvina e malvidina), } \\
\text { flavonóides, taninos, vitaminas A, B1, } \\
\text { B2 e C; oxalato de cálcio, resinas e } \\
\text { aminoácidos. }\end{array}$ & $\begin{array}{l}\text { Antiinflamatória, emoliente, } \\
\text { demulcente, adstringente, béquica, } \\
\text { laxativa e vulnerária. }\end{array}$ & $12 / 03 / 05$ \\
\hline $\begin{array}{c}\text { Piper } \\
\text { umbellatun }\end{array}$ & Pariparoba & $\begin{array}{l}\text { Óleo essencial, substâncias } \\
\text { fenólicas, esteróides, mucilagens e } \\
\text { pigmentos. }\end{array}$ & $\begin{array}{l}\text { Estimulante das funções hepáticas, } \\
\text { estomacais, pancreáticas e do baço. } \\
\text { Afecção das vias respiratórias, } \\
\text { maturação de furúnculo, } \\
\text { queimaduras superficiais, dores de } \\
\text { cabeça e reumatismo. }\end{array}$ & $07 / 03 / 05$ \\
\hline
\end{tabular}


TABELA 1. Relação dos nomes científicos e populares, constituintes ativos, ações farmacológicas e data da coleta das plantas estudadas, dados fornecidos pela empresa no certificado de análise.

\begin{tabular}{|c|c|c|c|c|}
\hline $\begin{array}{c}\text { Nome } \\
\text { científico }\end{array}$ & $\begin{array}{c}\text { Nome } \\
\text { popular }\end{array}$ & $\begin{array}{l}\text { Constituintes } \\
\text { ativos }\end{array}$ & $\begin{array}{l}\text { Ações } \\
\text { farmacológicas }\end{array}$ & $\begin{array}{l}\text { Data de } \\
\text { coleta }\end{array}$ \\
\hline $\begin{array}{l}\text { Solidago } \\
\text { microglossa }\end{array}$ & Arnica & $\begin{array}{l}\text { Óleo essencial, triterpenos, princípios } \\
\text { amargos, flavonóides, taninos, } \\
\text { resinas, cumarinas, ceras e } \\
\text { alcalóides. }\end{array}$ & $\begin{array}{l}\text { Tem como principal ação ser: } \\
\text { antiinflamatório, vulneraria tônica, } \\
\text { estimulante, revulsiva, anti-séptica e } \\
\text { analgésica. }\end{array}$ & $03 / 04 / 05$ \\
\hline $\begin{array}{l}\text { Pneumus } \\
\text { boldus }\end{array}$ & $\begin{array}{l}\text { Boldo do } \\
\text { Chile }\end{array}$ & $\begin{array}{l}\text { Óleo essencial (eucaliptol, ascaridol, } \\
\text { cinel, eugenol e alfa-pineno), } \\
\text { alcalóides, taninos, glicosídeos } \\
\text { flavônicos, gomas e terpenos. }\end{array}$ & $\begin{array}{l}\text { Eupéptico, colagoga, diurético, } \\
\text { afecções gástricas, estimulante da } \\
\text { digestão, e afecções do fígado. }\end{array}$ & $12 / 03 / 05$ \\
\hline
\end{tabular}

$\mathrm{Nl}$ : Não informado

A Tabela 2 apresenta os resultados obtidos nos experimentos de citotoxicidade dos extratos das plantas. Os extratos que apresentaram a menor toxicidade foram Equisetum arvense, Solanum paniculatum e Piper umbellatun, com CMNC igual a $2.000 \mu \mathrm{g} \mathrm{mL}^{-1}$. Já o EE de Peumus boldus apresentou maior toxicidade com CMNC igual a $62,5 \mu \mathrm{g} \mathrm{mL}^{-1}$. As outras plantas estudadas apresentaram $\mathrm{CMNC}$ entre $250 \mu \mathrm{g} \mathrm{mL}^{-1}$ a $1.000 \mu \mathrm{g} \mathrm{mL}^{-1}$.

Os resultados dos testes antivirais também se encontram na Tabela 2 e Figura 1. Entre os extratos testados, EA de Peumus bolduse Solanum paniculatum apresentaram atividade antiviral contra o SuHV-1 com IIV de 1,96 e 1,99, respectivamente representando uma porcentagem de inibição de $98 \%$ para ambos. Apenas o extrato EA de Peumus boldus apresentou atividade antiviral contra o herpesvírus bovino, com o IIV de 2,19 e porcentagem de inibição de $99 \%$.

\section{DISCUSSÃO}

No presente trabalho, os testes de citotoxicidade e de antiviral dos extratos de plantas foram avaliados em cultura celulares. Segundo Flint et al. (2004), as culturas celulares são muito eficazes para determinar a citotoxicidade dos extratos vegetais e para o estudo das relações parasita-hospedeiro. Os extratos devem apresentar-se o mínimo citotóxico possível e não induzir resistência viral e se possível interferir apenas nos processos moleculares dos vírus, sem afetar os processos metabólitos celulares (Gutiérrez, 2002). O extrato etanólico de boldo do Chile se mostrou o mais citotóxico de todos os extratos. Provavelmente, isto se deve à extração de substâncias menos polares, diferentes das encontradas nos extratos aquosos, e talvez mais tóxicas ou ainda pela presença residual de etanol utilizado durante a obtenção do extrato. Em testes

TABELA 2. Nome científico e popular, tipo de extrato, citotoxicidade e atividade antiviral das plantas testadas contra herpesvírus suíno e bovino em células de rim bovino MDBK.

\begin{tabular}{lcccccc}
\hline $\begin{array}{c}\text { ESPÉCIE } \\
\text { (Nome popular) }\end{array}$ & TIPO & $\begin{array}{c}\text { CMNC } \\
(\mu \mathbf{g ~ m L} \text { }-1)\end{array}$ & $\begin{array}{c}\text { IIV } \\
\text { SuHV-1 }\end{array}$ & Pl\% & $\begin{array}{c}\text { IIV } \\
\text { BoHV-1 }\end{array}$ & Pl\% \\
\hline Cymbopogon citratus (Capim Santo) & EA & 250 & 0 & 0 & 0,24 & 43 \\
Equisetum arvense (Cavalinha) & EA & 2000 & 0 & 0 & 0,74 & 82 \\
Malva sylvestris (Malva) & EA & 500 & 0,88 & 86 & 0 & 0 \\
Mikania glomerata (Guaco) & EA & 500 & 0,50 & 68 & 0,24 & 43 \\
Peumus boldus (Boldo do Chile) & EA & 250 & 1,96 & 98 & 2,19 & 99 \\
& EE & 62,5 & 0 & 0 & 0,50 & 68 \\
Piper umbellatun (Pariparoba) & EA & 2000 & 0,01 & 2 & 0 & 0 \\
Solanum paniculatum (Jurubeba) & EA & 2000 & 1,99 & 98 & 1,00 & 90 \\
Solidago microglossa (Arnica) & EA & 1000 & 0,26 & 44 & 0,24 & 43 \\
\hline
\end{tabular}

EA: extrato aquoso ; EE: extrato etanólico; CMNC:Concentração máxima não citotóxica; IIV: índice de inibição viral; PI\%: porcentagem de inibição. 


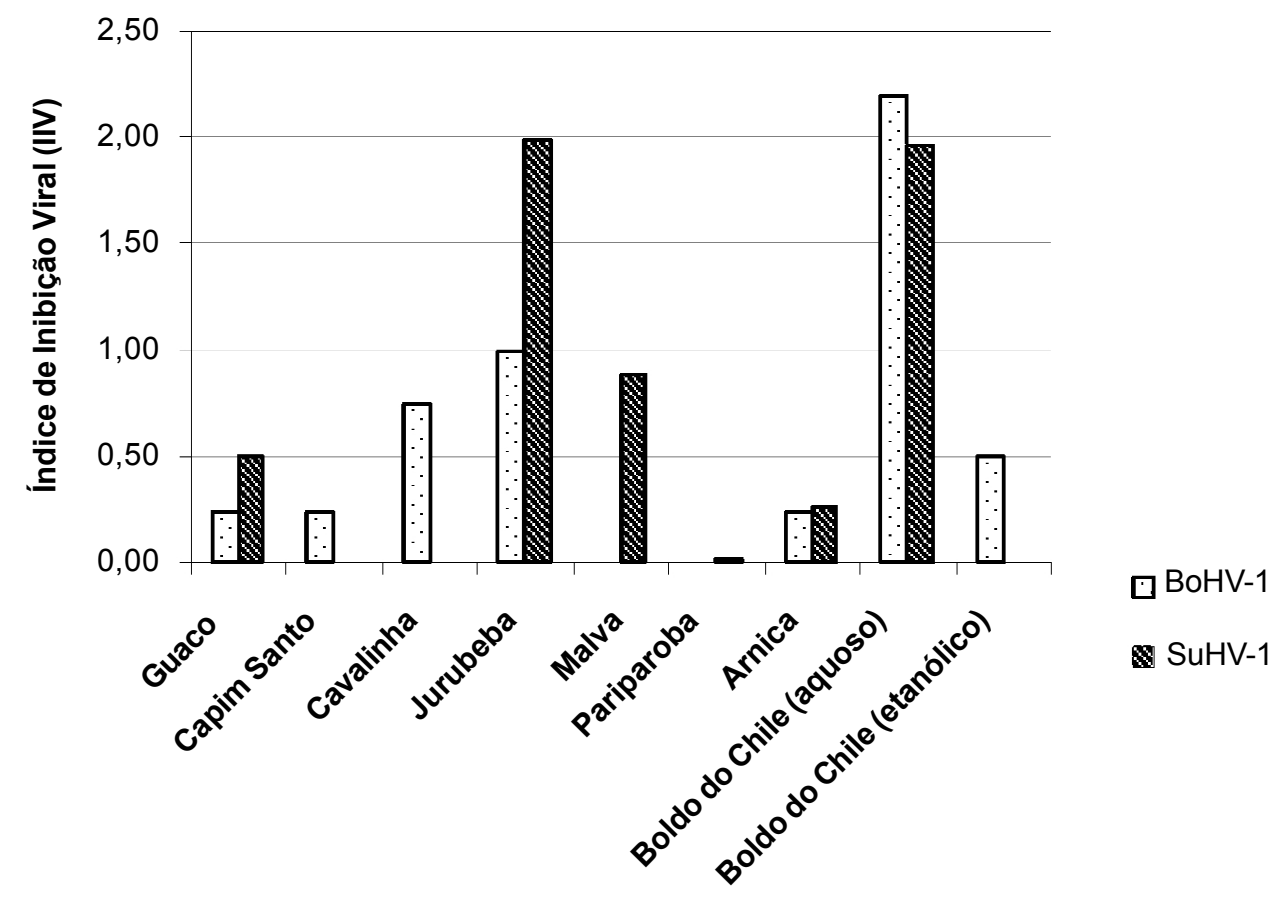

Extratos

FIGURA 1. Atividade antiviral de extratos de plantas testadas contra herpesvírus bovino e suíno em células MDBK.

antivirais o principal enfoque é escolher o extrato capaz de reduzir ou inibir esse efeito, numa concentração que não seja tóxica. Esses testes, especialmente o de triagem, têm como objetivo empregar uma metodologia, rápida, simples, de baixo custo e capaz de gerar informações úteis e confiáveis sobre o extrato escolhido, a fim de realizar estudos mais elaborados (Cechinel Filho \& Yunes, 1998; Simoni, 2003). Assim, as culturas celulares são as mais empregadas para a triagem de substâncias antivirais durante a seleção de prováveis inibidores.

Diversos trabalhos relatam o potencial farmacológico destas plantas na medicina popular. As folhas de guaco são utilizadas para o tratamento de afecções do aparelho respiratório e diminuir a febre. A parte aérea do capim santo é indicada para dores em geral, flatulência, disfunções gástricas e nervosismo. Folhas de cavalinha e de malva são utilizadas como antiinflamatórios e adstringentes; e as folhas de jurubeba como febrífugo e cicatrizante. A pariparoba é utilizada em casos de queimaduras superficiais e dores de cabeça. As folhas e flores da arnica são indicadas em casos de traumatismos, afecções do estômago e má digestão, e o boldo do Chile em casos de distúrbios gastrintestinais (Sartório et al., 2000; Teske \& Trentini, 2001; Nicoletti et al., 2007). A utilização das folhas na preparação de todos os extratos foi baseada não só pelas descrições acima, mas para se estabelecer um padrão de estudo independente do uso ou não desta parte na medicina popular. Cechinel \& Yunes (1998) relatam que a constituição química, na maioria dos casos, difere em relação às distintas partes da planta.

Apesar da variedade de metabólitos e de ações farmacológicas destas plantas, poucos estudos descrevem o potencial antiviral. Gutiérrez (2002) cita o composto solanina, esteróide glucoalcalóide presente em fruto da mesma família da jurubeba (Solanaceae), que inibiu o vírus do mosaico de tabaco. Di Stasi et al. (1996) afirmam que uma dada classe química de substâncias pode ocorrer em um gênero ou família. Além disso, o certificado de análise das plantas mostra que $S$. paniculatum possui saponinas como um dos constituintes ativos. Simões et al. (2004) relatam que as saponinas, presentes em algumas plantas, apresentam atividade antiviral e são também solúveis em água. Neste estudo, o extrato de folhas de $S$. paniculatum apresentou atividade antiviral contra SuHV-1. Portanto, este composto pode provavelmente estar relacionado com as propriedades antivirais observada no extrato aquoso da jurubeba.

As diferentes polaridades dos princípios ativos dos extratos tornam a escolha do solvente de fundamental importância para a obtenção. Assim, solventes são utilizados para a extração de 
determinados metabólitos secundários com polaridades diversas e podem fornecer a indicação do tipo de substância responsável por dada atividade biológica. Neste trabalho todos os extratos foram preparados em água, além do extrato de Peumus boldus que foi preparado também em etanol. Backhouse et al. (1994) descreveram o alcalóide boldina com atividade antiherpética. Yunes \& Calixto (2001) afirmam que alcalóides geralmente não são solúveis em água e estão presentes, principalmente, em extratos etanólicos, devido à hidrofobicidade das moléculas. Entretanto foi no extrato aquoso de boldo que houve atividade antiviral contra os dois herpesvírus e que foi perdida na extração com etanol. Portanto, devem existir outras substâncias no boldo do Chile, além do alcalóide boldina, que apresentam atividade antiviral. Dentre estas, Simões et al. (2004) citam os taninos e os glicosídeos flavônicos, que além de serem solúveis em água, apresentam atividade antiviral. Esses compostos são também constituintes presentes no boldo e em vista disso podem ser os responsáveis pela atividade encontrada no extrato aquoso.

Segundo Yunes \& Calixto (2001), estudos in vitro são normalmente mais rápidos e baratos, uma vez que pouca quantidade de amostras do material vegetal a ser testado é o suficiente para realizar o experimento. Além disso, fornecem resultados quantitativos, os mecanismos de ação dos extratos e/ou princípios ativos isolados são facilmente analisados e as variáveis podem ser controladas, 0 que facilita a reprodutibilidade dos ensaios. Mas posteriormente a esses estudos, experimentos "in vivo" devem ser realizados para confirmação da ação farmacológica das plantas, pois os efeitos obtidos nas culturas de células podem ou não ser observados, nos estudos realizados em animais.

Atualmente, existem empresas que cultivam plantas medicinais para uso comercial, sendo que suas observações sobre uso e a eficácia das plantas, são de origem populares e prescritos com freqüência, pelos efeitos medicinais que produzem. Muitas delas têm alguns constituintes químicos conhecidos e estudados cientificamente (Maciel et al. 2002). Assim, o uso de extratos disponíveis comercialmente de empresa que cultiva plantas medicinais favorece a realização dos experimentos pelo fato de serem de fácil acesso, de boa qualidade e de grande produção e cultivo, sem causar danos à natureza. Pois o elevado consumo de plantas medicinais mostra a necessidade da produção de alto nível técnico, diversificada e sem o uso de agroquímicos (Sartório et al., 2000).

Nos experimentos realizados no presente trabalho foram utilizados extratos preparados a frio onde as espécies $S$. paniculatum e $P$. boldus apresentaram potencial antiviral. Entretanto, a maioria dos extratos vegetais utilizados na medicina popular é de uso interno e preparados na forma de chá por infusão (Sartório et al., 2000). Em vista disso, algumas plantas moídas -foram preparadas a quente (dados não mostrados) exceto o de boldo por indisponibilidade de material. Observou-se atividade antiviral na espécie $S$. paniculatum e também na $S$. microglossa para o BoHV-1 dos extratos a quente e que não foi encontrado nos extratos a frio. Yunes \& Calixto (2001), afirmam que fatores externos, como a temperatura, podem alterar os compostos químicos, e consequentemente, ativar ou inibir os princípios ativos das plantas.

\section{CONCLUSÃO}

Extratos de plantas medicinais, disponíveis comercialmente, podem ser uma alternativa de baixo custo e de alta qualidade, na pesquisa de fitoterápicos com potencial antiviral desde que sejam produzidos segundo as boas práticas de fabricação e controle.

\section{AGRADECIMENTO}

Ao CNPq, pela bolsa de iniciação científica Programa PIBIC/CNPq/IB concedida à Vivian Massayo Kaziyama. A professora Rita Heloisa da Costa Yoem da Universidade Metodista pelo envolvimento neste trabalho e pelo fornecimento do material vegetal.

\section{REFERÊNCIA}

ACKERMANN, M.; ENGELS, M. Pro and contra IBReradication. Veterinary Microbiology, v.113, p.293-302, 2006.

BACKHOUSE, N. et al. Anti-inflammatory and antipyretic effects of boldine. Agents Actions, v.42, n.3-4, p.114-7, 1994.

BARBOSA, A.C.V.C.; BRITO, W.M.E.D.; ALFAIA, B.T. Soroprevalência e fatores de risco para infecção pelo herpesvírus bovino tipo 1 (BHV-1) no Estado de Goiás, Brasil. Ciência Rural, v.35, n.6, p.1368-73, 2005.

CECHINEL F.V.C.; YUNES, R.A. Estratégias para a obtenção de compostos farmacologicamente ativos a partir de plantas medicinais. Conceitos sobre modificação estrutural para otimização da atividade. Química Nova, v.21, n.1, p.99-105, 1998.

CUNHA, E.M.S. et al. Eficácia de vacina inativada contra a doença de Aujeszky: infecção experimental de suínos. Brazilian Journal of Veterinary Research and Animal Science, v.35, n.4, p.188-94, 1998.

Del FAVA, C.D. et al. Erradicação do herpesvírus bovino 1 (BHV-1) de um rebanho bovino leiteiro em manejo semi-intensivo. Pesquisa Veterinária Brasileira, v.18, n.2, p.65-8, 1998.

DI STASI, L.C. et al. Plantas medicinais: arte e ciência. 
um guia de estudo interdisciplinar. 1.ed. São Paulo: Universidade Estadual Paulista, 1996. 231p.

FONSECA JUNIOR, A.A. et al. Diagnóstico e genotipagem do vírus da pseudoraiva por NESTED-PCR e análise de restrição enzimática. Ciência Rural, v.40, n.4, p.921-7, 2010.

FLINT, S.J. et al. Prevention and control of viral diseases. In: FLINT, S.J. et al. (Eds.). Principles of Virology. 2.ed. Washington: ASM Press, 2004. p.703-57.

GROFF, F.H.S. et al. Epidemiologia e controle dos focos da doença de Aujeszky no Rio Grande do Sul, em 2003. Pesquisa Veterinária Brasileira, v.25, n.1, p.25-30, 2005. GUTIÉRREZ, R.M.P. Compuestos com actividad antiviral. In: GUTIÉRREZ, R.M.P. (Ed.). Compuestos aislados de plantas con actividad antiinflamatoria, antiviral e hipoglucemiante. México: Instituto Politécnico Nacional, 2002. p.79-119.

JONES, C. Herpesvírus type 1 and bovine herpesvírus 1 latency. Clinical Microbiology Review, v.16, n.1, p.79-95, 2003.

KOSEKI, I. et al. Antiviral activity of plant extracts against aphtovirus, pseudorabies virus and pestivirus in cell cultures. Microbios Letters, v.44, n.1, p.19-30, 1990. MACIEL, M.A.M. et al. Plantas medicinais: a necessidade de estudos multidisciplinares. Química Nova, v.25, n.3, p.429-38, 2002.

MÉDICI, K.C.; ALFIERI, A.A.; ALFIERI, A.F. Prevalência de anticorpos neutralizantes contra o herpesvírus bovino do tipo 1, decorrente de infecção natural, em rebanhos com distúrbios reprodutivos. Ciência Rural, v.30, n.2, p.347-50, 2000.

NICOLETTI, M.A. et al. Principais interações no uso de medicamentos fitoterápicos. Infarma, v.19, n.1/2, p.3240, 2007.
REED, J.H.; MUENCH, H. A simple method for estimating fifty percent endpoints. American Journal of Tropical Medicine and Hygiene, v.27, p.493-6, 1938.

SARTÓRIO, M.L. et al. Cultivo orgânico de plantas medicinais. Viçosa: Aprenda fácil, 2000. 258p.

SILVA, D. et al. Caracterização antigênica e molecular de oito amostras do vírus da doença de Aujeszky isoladas no estado do Rio Grande do Sul em 2003. Pesquisa Veterinária Brasileira, v.25, n.1, p.21-4, 2005. SIMÕES, C.M.O. et al. Farmacognosia: da planta ao medicamento. 5.ed. Porto Alegre/Florianópolis: Editora UFRGS/UFSC, 2004. 1102p.

SIMONI, I.C. Tratamentos antivirais. Biológico, v.65, n.1/2, p.41-4, 2003.

SIMONI, I.C. et al. Evaluation of the antiviral activity of Brazilian cerrado plants against animal viruses. Virus Review and Research, v.12, n.1/2, p.25-31, 2007.

SPILKI, F.R. et al. Avaliação comparativa da patogenicidade de herpesvírus bovinos tipo 1 (BHV-1) subtipos 1 (BHV-1.1) e 2a (BHV-1.2a). Pesquisa Veterinária Brasileira, v.24, n.1, p.43-9, 2004.

STRAUB, O.C. Advances in BHV-1 (IBR) research. Dtsch Tierarztl Wochenschr, v.108, n.10, p.419-22, 2001.

TAKIUCHI, E. et al. Otimização de reação em cadeia pela polimerase (Semi Nested - PCR) para a detecção do herpesvírus bovino tipo $1 \mathrm{em}$ fragmentos de órgãos fetais e em sêmen de bovinos naturalmente infectados. Semina: Ciências Agrárias, v.24, n.1, p.43-56, 2003. TESKE, M.; TRENTINI, A.M.M. Herbarium compêndio de fitoterapia. 4.ed. Curitiba: Herbarium Laboratório Botânico Ltda, 2001. 317p.

YUNES, R.; CALIXTO, J.B. Plantas medicinais sob a ótica da química medicinal moderna. Chapecó: Argos, 2001. 524p. 